\title{
The comovement of US and UK stock markets*
}

\author{
Tom Engsted and Carsten Tanggaard \\ Department of Finance, The Aarhus School of Business, Fuglesangs allé 4, \\ DK-8210 Aarhus V., Denmark. \\ E-mail: tom@asb.dk (Engsted), cat@asb.dk (Tanggaard). \\ January 2002.
}

\begin{abstract}
US and UK stock returns are highly positively correlated over the period 1918-1999. Using VAR-based variance decompositions, we investigate the nature of this comovement. Excess return innovations are decomposed into news about future dividends, real interest rates, and excess returns. We find that the latter news component is the most important in explaining stock return volatility in both the US and the UK and that stock return news is highly correlated across countries. This is evidence against Beltratti and Shiller's (1993) finding that the comovement of US and UK stock markets can be explained in terms of a simple present value model. We interpret the comovement as indicating that equity premia in the two countries are hit by common real shocks.
\end{abstract}

Keywords: Comovement of stock returns; Variance decomposition; VAR model; Bias-correction; Bootstrap simulation.

JEL Codes: C32, G12

\section{Introduction}

Explaining stock price movements over long time periods is one of the big challenges in empirical finance. According to standard textbook theory, real stock prices are determined by expected real dividends discounted by a constant discount rate. However, based on yearly data over many decades, the evidence against this simple present value model (PVM) is overwhelming. Discount rates are varying over time, and standard

\footnotetext{
${ }^{*}$ We would like to thank Jesper Rangvid and participants at the Arne Ryde Workshop in Empirical Finance in Lund for useful comments, and Dirk Nitzsche for supplying part of the UK data used in this paper. The research is supported by a grant from the Danish Social Science Research Council.
} 
models from finance theory have generally not been able to explain this time-variation, see e.g. Campbell and Shiller (1988), Lund and Engsted (1996), and Cuthbertson et al. (1997).

Most studies in this area have focused on individual countries. The literature on international comovement of stock prices and comovement of fundamentals over long time periods is sparse. Among the exceptions are Kasa (1992) and Engsted and Lund (1997) who find that international stock prices are cointegrated, and they analyze whether this lowfrequency comovement can be explained in terms of cointegration among dividends. Unfortunately, the results in these two studies are quite ambiguous. Shiller (1989) presents a detailed analysis of the comovement of US and UK stock markets over the period 1919-1987. Although stock prices and dividends in the two countries show a quite similar movement over time, a formal analysis reveals that this comovement cannot be explained in terms of simple PVM's with constant discount rates. US and UK stock prices move closer together than can be explained in terms of the comovement in dividends. However, when discount rates are allowed to vary with a short term interest rate, the excess comovement disappears. Beltratti and Shiller (1993) extend the analysis in Shiller (1989) in various directions, but basically they obtain the same qualitative results. They do find, however, that the underlying PVM's are statistically rejected. Strictly speaking, the finding that the comovement of US and UK stock markets is in accordance with a PVM in which the discount rate varies with the short term interest rate, is inconsistent with the fact that the same model cannot explain stock price movements in the countries treated in isolation. ${ }^{1}$

The purpose of the present paper is to analyze the comovement of US and UK stock markets further. We will use the same data as in Shiller (1989) and Beltratti and Shiller (1993) (updated to 1999), but in contrast to those papers we do not attempt to explain comovement within specific economic models (e.g. PVM's). Instead, we decompose stock return innovations in the two countries into various 'news' components (dividend news, real interest rate news, and stock return news), and then analyze how these components move together across countries. As shown by Campbell (1991), assuming only the absence of speculative bubbles, unexpected excess stock returns can be decomposed into changes in expectations ('news') of future dividends, real interest rates, and excess stock returns. Campbell (1991) and Campbell and Ammer

\footnotetext{
${ }^{1}$ In addition to the literature mentioned above, a number of studies have analyzed the comovement of international stock markets over shorter time periods. Many of these studies, however, look only at stock prices or returns, and do not investigate comovement in the fundamental variables (e.g. dividends).
} 
(1993) find that news about future excess returns is the dominating force behind movements in US stock returns, with news about future dividends and real interest rates being less important (although nonnegligible). Cuthbertson et al. (1998) find similar results for the UK. It would be interesting to investigate how these news components are related across countries. Since US and UK stock returns are highly positively correlated, the underlying forces behind the movements in returns in the two countries must also be highly positively correlated. A natural conjecture is that since stock return news is the dominating force behind market movements in both the US and the UK, stock return news in the US should be highly correlated with stock return news in the UK. Similarly, it would be interesting to see how dividend news and real interest rate news are related across countries.

We use vector-autoregressive (VAR) models to answer these questions. Since the variance decompositions require estimates of infinitehorizon expectations, an empirical model is needed to compute these expectations. The basic VAR methodology from Campbell (1991) is applied, but extended in various directions. First, the VAR model includes data from both the US and the UK stock markets. This makes it possible to analyze the dynamic linkages between the two markets. Second, the VAR parameter estimates are adjusted for small-sample bias. This is potentially important since Bekaert et al. (1997) have found that inference in VAR models can be highly sensitive to whether parameter estimates are bias-adjusted or not. Third, since estimated precision measures based on asymptotic approximations can be highly misleading in small samples, bootstrap simulation is used for computing small-sample standard errors and confidence intervals of the VAR generated statistics.

Our analysis is similar in spirit to the analysis conducted by Ammer and Mei (1996). They also construct a VAR-based variance decomposition of US and UK stock returns, with the purpose of measuring financial and real economic linkages between the two countries. However, their VAR-models, datasets, and econometric methodology differ in important ways from ours. We will compare our framework and results with the framework and results in Ammer and Mei.

The main empirical finding in our paper is that news about future excess returns (risk-premia) is the main determinant of stock market volatility in both the US and the UK, and that this news component is highly cross-country correlated which helps explain the high degree of comovement of US and UK stock markets. This indicates that equity risk premia in the two countries are hit by common real shocks.

The rest of the paper is organized as follows. In section 2 we describe the basic methodology and compare it with the methodology in Ammer 
and Mei (1996). Section 3 reports the empirical results. Finally, section 4 contains some concluding remarks where we relate our results to the asset pricing model in Campbell and Cochrane (1999).

\section{Return variance decomposition and econometric methodology}

In section 2.1 we describe the VAR-based variance decomposition. Section 2.2 gives a brief description of the small-sample bias-correction of the VAR parameter estimates and of the bootstrap technique used to compute small-sample standard errors and confidence intervals. Section 2.3 compares our methodology with the methodology in Ammer and Mei (1996).

\subsection{VAR-based variance decomposition}

The starting point for the subsequent discussion is the following expression for the innovation in stock market excess returns (c.f. Campbell, 1991):

$e_{t+1}-E_{t} e_{t+1}=\left(E_{t+1}-E_{t}\right)\left\{\sum_{j=0}^{\infty} \rho^{j} \Delta d_{t+1+j}-\sum_{j=0}^{\infty} \rho^{j} r_{t+1+j}-\sum_{j=1}^{\infty} \rho^{j} e_{t+1+j}\right\}$

$e_{t}$ is the log gross stock return from $t-1$ to $t$, minus the one-period continuously compounded interest rate. $r_{t}$ is the log gross real interest rate from $t-1$ to $t$. $d_{t}$ denotes real dividends paid during period $t$. $E_{t}$ and $\Delta$ denote the conditional expectations operator and the firstdifference operator, respectively, and $\rho$ is a constant slightly less than one.

Equation (1) follows from the basic dynamic accounting identity that (in linearized form) relates current stock prices to future stock prices, dividends, and returns, see Campbell (1991). There is no economic theory in (1), except that rational speculative bubbles are ruled out. It says that positive (negative) unexpected excess stock returns from $t$ to $t+1$ must be due to news arriving to the market between $t$ and $t+1$ that future dividend growth will be higher (lower) than expected, and/or future real interest rates will be lower (higher) than expected, and/or future excess returns will be lower (higher) than expected. The combination of the latter two news components yields news about future real stock returns. The intuition for the negative relationship between news about future real returns and return innovations today is that, for a fixed dividend stream, higher future returns can only come about by a fall in current stock prices, i.e. a negative return innovation. 
Equation (1) holds for each individual stock market. In order to simplify the notation, denote by $\widetilde{e}_{t+1}^{i} \equiv e_{t+1}^{i}-E_{t} e_{t+1}^{i}, \widetilde{e}_{d, t+1}^{i} \equiv\left(E_{t+1}-\right.$ $\left.E_{t}\right) \sum_{j=0}^{\infty} \rho_{i}^{j} \Delta d_{t+1+j}^{i}, \widetilde{e}_{r, t+1}^{i} \equiv\left(E_{t+1}-E_{t}\right) \sum_{j=0}^{\infty} \rho_{i}^{j} r_{t+1+j}^{i}$, and $\widetilde{e}_{e, t+1}^{i} \equiv$ $\left(E_{t+1}-E_{t}\right) \sum_{j=1}^{\infty} \rho_{i}^{j} e_{t+1+j}^{i}$, where $i$ denotes either US or UK. Then (1) can be written as

$$
\tilde{e}_{t+1}^{i}=\tilde{e}_{d, t+1}^{i}-\tilde{e}_{r, t+1}^{i}-\widetilde{e}_{e, t+1}^{i} \quad, \quad i=u s, u k
$$

The conditional expectations in (1) are computed from a VAR model. The VAR system needs to include $e_{t}^{i}$ and at least either $\Delta d_{t}^{i}$ or $r_{t}^{i}$ in order to be able to compute each of the components in (2). However, we also include the log dividend-price ratio, $\delta_{t}^{i}$, because previous studies have found that this variable has significant predictive ability for future stock returns. Our benchmark VAR model includes the following six variables: $e_{t}^{u s}, r_{t}^{u s}, \delta_{t}^{u s}, e_{t}^{u k}, r_{t}^{u k}$, and $\delta_{t}^{u k}$. Thus, if we collect these variables in the vector $z_{t}$, then the first-order VAR model for $z_{t+1}$ is ${ }^{2}$

$$
z_{t+1}=A z_{t}+\omega_{t+1}
$$

where $A$ is the VAR parameter matrix and $\omega_{t+1}$ is the vector of error terms. Note that the US and UK variables are included in one comprehensive VAR system, thereby making it possible to analyze the dynamic linkages between the two markets. In the empirical analysis we will test whether the US (UK) variables have significant predictive ability for the UK (US) stock returns.

From (3) the VAR estimate of $z_{t+1}-E_{t} z_{t+1}$ is $\omega_{t+1}$. Similarly, the VAR estimate of $\left(E_{t+1}-E_{t}\right) z_{t+1+j}$ is $A^{j} \omega_{t+1}$. Therefore, if we define row selection vectors $g_{1}^{u s}, g_{2}^{u s}, g_{1}^{u k}$, and $g_{2}^{u k}$ that pick out, respectively, the first, second, fourth, and fifth element of $z_{t}$, VAR estimates of each of the components in (2) are given as

$$
\begin{array}{ll}
\widetilde{e}_{t+1}^{i}=g_{1}^{i} \omega_{t+1} & i=u s, u k \\
\widetilde{e}_{e, t+1}^{i}=\rho_{i} g_{1}^{i} A\left(I-\rho_{i} A\right)^{-1} \omega_{t+1} & i=u s, u k \\
\widetilde{e}_{r, t+1}^{i}=g_{2}^{i}\left(I-\rho_{i} A\right)^{-1} \omega_{t+1} & i=u s, u k \\
\widetilde{e}_{d, t+1}^{i}=\widetilde{e}_{t+1}^{i}+\widetilde{e}_{r, t+1}^{i}+\widetilde{e}_{e, t+1}^{i} & i=u s, u k
\end{array}
$$

\footnotetext{
${ }^{2}$ The generalization to the case with more than one lag is straightforward using the companion form. All variables in the VAR are measured in deviations from their unconditional means.
} 
where the VAR residuals and parameter estimates are inserted in $\omega_{t+1}$ and $A$, respectively. Note that the dividend news component, $\widetilde{e}_{d, t+1}^{i}$, is obtained as a residual from the other three components in the dynamic accounting identity (2). We will also report results for a VAR system where $\Delta d_{t}^{i}$ is included instead of $r_{t}^{i}$. In that case $\widetilde{e}_{d, t+1}^{i}$ is generated as in (6), i.e. $\widetilde{e}_{d, t+1}^{i}=g_{2}^{i}\left(I-\rho_{i} A\right)^{-1} \omega_{t+1}$, and $\widetilde{e}_{r, t+1}^{i}$ is obtained as a residual from (2): $\widetilde{e}_{r, t+1}^{i}=\widetilde{e}_{d, t+1}^{i}-\widetilde{e}_{e, t+1}^{i}-\widetilde{e}_{t+1}^{i}$. As noted by Campbell and Ammer (1993), the VAR approach is crucially dependent on $z_{t+1}$ being to some extent predictable from $z_{t}$. Otherwise all the variability of $\widetilde{e}_{t+1}^{i}$ will be attributed to the component treated as a residual. Hence, if one finds that most of the variability of $\widetilde{e}_{t+1}^{i}$ is due to e.g. the $\widetilde{e}_{d, t+1}^{i}$ component, and this component is obtained as a residual, then its large estimated magnitude may be spurious simply as the result of insufficient predictability in the VAR system. By analyzing different systems where either dividends or real interest rates are treated as a residual, we hope to be able to discover such spuriousness if it occurs. ${ }^{3}$

To measure the relative magnitude of each of the news components, one possibility would be to normalize the variances and covariances of the components by the variance of $\widetilde{e}_{t+1}^{i}$. Since the news components are not necessarily independent, however, these measures may be difficult to interpret. Therefore we measure the relative magnitudes by orthogonalizing (using a Cholesky decomposition) the components and then measure the $R^{2}$ values in regressions of $\tilde{e}_{t+1}^{i}$ on each of the orthogonalized components. The sum of the $R^{2}$ values will then add up to one so that each individual $R^{2}$ number can be interpreted as the fraction of the return innovation variance explained by that particular news component. $^{4}$ To measure the degree of comovement of the various news components, we follow Campbell and Ammer (1993) and simply report

\footnotetext{
${ }^{3}$ In accordance with most previous literature [e.g. Campbell (1991), Campbell and Ammer (1993), Ammer and Mei (1996), Patelis (1997), Cuthbertson et al. (1998), Engsted and Tanggaard (2001a)], we obtain one of the news components as a residual to make sure that the dynamic accounting identity (2) holds exactly. Thereby we explicitly rule out the possibility that rational speculative bubbles may be a source of variation in stock prices. By contrast, Engsted and Tanggaard (2001b) estimate all the components in (2) directly from a VAR model that includes both $r_{t}$ and $\Delta d_{t}$, and test whether the variance of the left-hand side, $\widetilde{e}_{t+1}$, is equal to the variance of the right-hand side, $\widetilde{e}_{d, t+1}-\widetilde{e}_{r, t+1}-\widetilde{e}_{e, t+1}$. Rejection of this hypothesis implies the presence of rational bubbles. However, on US and UK stock market data the null hypothesis of no bubbles cannot be rejected, see Engsted and Tanggaard (2001b) for details.

${ }^{4}$ The Cholesky decomposition is not independent of the ordering of the variables and we report results based on all possible orderings. If the results are sensitive to the precise ordering, we will look at the variances and covariances of the unorthogonalized news components to help judging which of the components is the most important.
} 
their pairwise correlation coefficients.

\subsection{Bias-correction and small-sample precision mea- sures}

Bekaert et al. (1997) have argued that the small-sample bias that characterizes VAR parameter estimates may seriously distort inference in VAR models. Thus, before calculating the components in (2), we correct the VAR parameter estimates for small-sample bias using Pope's (1990) analytical bias formula. However, we modify Pope's adjustment by invoking Kilian's (1998) method for avoiding unit or explosive roots.

We use bootstrap simulation to compute small-sample standard errors and confidence intervals of the VAR generated statistics, i.e. correlation coefficients and $R^{2}$ values from the regressions with the orthogonalized components. Basically, Bose's (1988) resampling technique is used in the same way as in Engsted and Tanggaard (2001a), and confidence intervals are computed using a bias-correction method ( $B C$-intervals, see Hall, 1992)..$^{5}$

\subsection{Comparison with the Ammer-Mei methodolo- gy}

Ammer and Mei (1996) also make a VAR-based variance decomposition of US and UK stock returns and examine the comovement of news components. Their monthly dataset spans the period 1957-1989, and in the main part of their analysis they work with a VAR-model that includes US excess stock return, interest rate, and dividend-price ratio, UK stock return (expressed in dollars, and in excess of the US interest rate), dividend-price ratio, and, finally, the real exchange rate between the US and the UK. They find that news about future excess returns accounts for the bulk of stock market volatility in both countries, and that the excess return news components are highly cross-country correlated in the post Bretton Woods period 1973-1989, but not during the earlier period 1957-1972. On the other hand, the dividend news components are highly positively correlated during both sub-samples. ${ }^{6}$ They

\footnotetext{
${ }^{5}$ Details on the bias-correction of the VAR parameter estimates, and on the bootstrap procedure, are available from the authors upon request.

${ }^{6}$ A puzzling feature of Ammer and Mei's results is that the news about future real interest rates components seem to be perfectly correlated across countries (c.f. their Table V). This seems to be due to the fact that only US interest rates (and not UK interest rates) appear in the VAR, and that they compute the UK interest rate news component from the residuals of the US interest rate equation (c.f. the Appendix in Ammer and Mei). Thus, implicitly they assume that US and UK real interest rates are identical.
} 
interpret these results as implying closer financial linkages after the Bretton Woods currency arrangement was abandoned, while real economic linkages have remained more or less unchanged.

A potential problem with this interpretation is that Ammer and Mei use the comovement of the dividend news components as a measure of real economic integration, but dividend growth does not figure as a state variable of the VAR. As in the first of our VAR models, the dividend news component is obtained as a residual from the return innovation, return news, and interest rate news components. This implies that the dividend news component may be estimated spuriously high. The reason that Ammer and Mei do not include dividend growth directly in the VAR is that monthly dividends show a strong seasonal pattern. Since in our analysis we are working with annual data, we do not face this problem and, hence, in the second of our VAR models we include dividend growth directly. In any case, our analysis differs from Ammer and Mei's in that we follow Shiller (1989) and Beltratti and Shiller (1993) and look at long-term data that span several decades, and where we do not convert US and UK stock returns into a common currency. Thus, our analysis does not shed much light on financial integration between the two countries, but instead has the explicit purpose of examining comovement, caused by common real shocks, of the two stock markets, for which long-term annual data are better suited. If we find that news about future excess returns is the main cause of stock market volatility in both the US and the UK, and that these news components are highly correlated, it does not necessarily imply that the US and UK are highly financially integrated, but may instead be the result of risk-premia in the two countries being driven by real economic variables that are hit by common shocks. ${ }^{7}$ This interpretation is opposite to that given by Ammer and Mei.

Another important difference between Ammer and Mei and our paper is that Ammer and Mei's sample period ends in 1989 whereby they miss the stock market boom of the 1990's. Several authors have argued that the functioning of worlds stock markets in the last ten years has been dramatically different from the earlier periods. By including data from the 1990's we are able to investigate whether the recent stock market boom has altered the relative importance of the various news components, and whether the cross-country comovements have changed.

\footnotetext{
${ }^{7}$ According to standard consumption-based asset pricing models, risk-premia on stocks (excess stock returns) are driven by stock returns covariation with consumption growth, so shocks to consumption growth that are common for the US and the UK may induce common fluctuations in excess stock returns. (See also the concluding remarks in section 4).
} 
Finally, there are some important econometric differences between our analysis and Ammer and Mei's. As in most previous studies using VAR models, their VAR parameter estimates are standard leastsquares estimates, and the standard errors of the VAR generated statistics are computed using asymptotic approximations, i.e. the usual 'delta method'. Thus, their results may be infected by small-sample problems. We adjust the parameter estimates for small-sample bias and use bootstrap simulation to compute finite-sample precision measures.

\section{Empirical results}

The data to be used in this paper are basically identical to the data used in numerous prior studies, e.g. Bulkley and Tonks (1989), Shiller (1989), Shiller and Beltratti (1992), Beltratti and Shiller (1993), Lund and Engsted (1996), Engsted and Lund (1997), Cuthbertson et al. (1997, 1998), and Engsted (1998), but updated to 1999. For the US, the Standard and Poor Composite Stock Price Index and associated dividends are used to construct stock returns. The short-term interest rate is measured by the 4-6 month prime commercial paper rate. The consumption deflator for non-durables and services is used to compute real values. These data are available from Robert J. Shiller's web-page (www.econ.yale.edu/ ${ }^{\sim}$ shiller). For the UK, the de Zoete and Wedd value-weighted Equity Price Index and associated dividends are used to construct stock returns. The short-term interest rate is measured by the 3-month prime bill rate, and real values are computed using the implicit consumption deflator. The US and UK data cover the period 1918-1999.

The variables to be used in the VAR analyses need to be stationary. Augmented Dickey-Fuller tests (not reported; details are available upon request) show that US and UK excess stock returns, real interest rates, and log dividend-price ratios are stationary, except possibly for the US log dividend-price ratio, which appears to be borderline non-stationary. However, if we restrict the sample period to end in 1989, all variables are clearly stationary. The possible non-stationarity of $\delta_{t}^{u s}$ over the entire sample period seems to be due to the dramatic fall in this variable during the 1990s. This, of course, is just a reflection of the huge increases in US stock prices in recent years, increases which do not characterize dividends. Several authors, e.g. Shiller (2000), have argued that these stock price increases are due mainly to speculative bubbles in the US stock market. Equation (2) in section 2, which forms the basis for the empirical analysis, presumes that there are no such bubbles. Therefore, in addition to conducting the analysis for the whole period 1918-1999, we 
will also conduct a sub-sample analysis for the period $1918-1989 .{ }^{8}$ This will also ease comparison to the results in Beltratti and Shiller (1993) as their sample period is 1918-1989.

US and UK excess stock returns are highly positively correlated. ${ }^{9}$ Over the whole period 1918-1999 the correlation is 0.542, and the correlation coefficient remains highly positive across various sub-periods (in the three sub-periods 1918-1945, 1943-1970, and 1973-1999, the correlations are $0.604,0.474$, and 0.638 , respectively). Thus, there is a high degree of comovement of the two national markets, and the purpose of the VAR analysis to be carried out in this section is to analyze in more detail the nature of this comovement. (Figure 1 shows excess stock returns in the two countries).

In determining the lag-length of the VAR models, we formally test lag-length restrictions using a likelihood ratio test with the small-sample correction suggested by Sims (1980) invoked. This results in a lag-length of three for both the 1918-1999 and 1918-1989 periods. Tables 1 to 6 report the results of the VAR analyses.

If we start by looking at the model which includes excess returns, real interest rates, and dividend-price ratio's for both countries, Table 1 shows that US and UK excess stock returns are highly predictable from the past. Furthermore, the US variables turn out to contain predictive power for UK excess returns, and vice versa, which points to important dynamic linkages between the two national markets. These results carry over to the VAR system where dividend growth replaces real interest rates, in the 1918-1989 period. However, for this VAR system covering the whole period 1918-1999, the UK variables do not contain significant explanatory power for US returns, and the US variables are only marginally significant in the $e_{t}^{u k}$ equation.

Table 2 reports the news variance decompositions for the 1918-1999 period where the VAR model contains the following variables: $z_{t}=\left[e_{t}^{u s}\right.$, $\left.r_{t}^{u s}, \delta_{t}^{u s}, e_{t}^{u k}, r_{t}^{u k}, \delta_{t}^{u k}\right]^{\prime}$. These decompositions are based on computing the innovation and news components as in (4) to (7) using the bias-corrected VAR parameter estimates and residuals. Although the $95 \%$ confidence intervals are quite wide, for the UK the variance decompositions based on the orthogonalized components unambiguously indicate that, independent of the ordering, $R^{2}\left(\widetilde{e}_{e}\right)$ is larger than $R^{2}\left(\widetilde{e}_{d}\right)$ and $R^{2}\left(\widetilde{e}_{r}\right)$. News about future excess returns accounts for between $43 \%$ and $81 \%$ of the

\footnotetext{
${ }^{8}$ Using the same data as in the present paper, Engsted and Tanggaard (2001b) find no evidence of rational bubbles in US and UK stock prices.

${ }^{9}$ The sample means (standard deviations) of the continuously compounded oneyear excess stock returns are $6.0 \%$ (17.8\%) and 6.7\% (20.0\%) for the US and the UK, respectively.
} 
variability of UK excess returns, while news about future dividends accounts for between $1 \%$ and $35 \%$, and news about future real interest rates accounts for between $2 \%$ and $22 \%$. For the US, the variance decompositions based on the orthogonalized components are highly sensitive to the ordering of the variables. However, in three of the six orderings $R^{2}\left(\widetilde{e}_{e}\right)$ accounts for $61 \%$ or more, and by looking at the unorthogonalized components, the ratio of the variance of news about future excess returns to the variance of excess return innovations, is much larger than the variance ratios for dividend news and real interest rate news. In addition, the covariance terms that include $\widetilde{e}_{e}$ are much larger than the covariance term for $\widetilde{e}_{d}$ and $\widetilde{e}_{r} \cdot{ }^{10}$ Thus, it seems that in both countries most of the variability in excess stock returns is due to news about future excess stock returns, while news about future dividends and real interest rates play a minor role.

Since US and UK excess stock returns are highly positively correlated, and since excess return news seems to be the dominating force behind movements in both markets, a natural conjecture is that $\widetilde{e}_{e}^{u s}$ and $\widetilde{e}_{e}^{u k}$ are also highly positively correlated. This is confirmed by the crosscorrelations reported in the upper part of Table 3. US excess return news and UK excess return news show a positive correlation of 0.89 over the period 1918-1999. Interestingly, however, real interes rate news and, to a lesser extent, dividend news, in the two countries are also highly correlated. Thus, apparently, it is comovement in all underlying forces that explains the high degree of comovement of the US and UK stock markets that is observed over the long period from 1918 to 1999.

In Table 4 we report the variance decompositions for the period 19181999 and with $z_{t}=\left[e_{t}^{u s}, \Delta d_{t}^{u s}, \delta_{t}^{u s}, e_{t}^{u k}, \Delta d_{t}^{u k}, \delta_{t}^{u k}\right]^{\prime}$, i.e. real interest rates are replaced by dividend growth in the VAR model, and in the lower part of Table 3 the pairwise correlations of the implied news components are reported. As seen, the results for this VAR system unambiguously indicate that in both the US and the UK news about future excess returns accounts for most of the variation in stock returns $\left(R^{2}\left(\widetilde{e}_{e}\right)\right.$ lies between $58 \%$ and $95 \%$ for the US, and between $60 \%$ and $86 \%$ for the UK), and the various news components are highly positively correlated across countries. These results confirm and strengthen the results from Table 2 and the upper part of Table 3.

Tables 5 and 6 and the last column of Table 3 report the results of the variance decompositions for the smaller sample period 1918-1989, i.e. the period which excludes the recent run-up in stock prices. These

\footnotetext{
${ }^{10} \operatorname{Var}\left(\widetilde{e}_{d}^{u s}\right) / \operatorname{Var}\left(\widetilde{e}^{u s}\right)=0.486 ; \operatorname{Var}\left(\widetilde{e}_{r}^{u s}\right) / \operatorname{Var}\left(\widetilde{e}^{u s}\right)=1.151 ; \operatorname{Var}\left(\widetilde{e}_{e}^{u s}\right) / \operatorname{Var}\left(\widetilde{e}^{u s}\right)=3.608 ;-$ $2 \operatorname{Cov}\left(\widetilde{e}_{d}^{u s}, \widetilde{e}_{r}^{u s}\right) / \operatorname{Var}\left(\widetilde{e}^{u s}\right)=-0.006 ;-2 \operatorname{Cov}\left(\widetilde{e}_{d}^{u s}, \widetilde{e}_{e}^{u s}\right) / \operatorname{Var}\left(\widetilde{e}^{u s}\right)=-0.450 ; 2 \operatorname{Cov}\left(\widetilde{e}_{r}^{u s}, \widetilde{e}_{e}^{u s}\right) /$ $\operatorname{Var}\left(\widetilde{e}^{u s}\right)=-3.737$.
} 
results are basically the same as for the whole period 1918-1999. Excess return news accounts for more than $60 \%$ of the return innovation variance in the UK. For the US the results are somewhat sensitive to the choice of VAR model and to the ordering of the variables in the Cholesky decomposition. However, in both VAR models excess return news accounts for most of the variation in return innovations in at least three of the six orderings, and inspection of the unorthogonalized news components (not reported) shows that the variance- and covariance ratio's involvolving $\widetilde{e}_{e}$ are much larger than the ratio's not involving $\widetilde{e}_{e}$. Thus, also for the smaller period 1918-1989 it seems that in both the US and the UK, news about future excess returns is the dominating force behind stock market volatility. In this period all individual news components are highly positively correlated across countries, although the cross-country correlations of $\tilde{e}_{e}^{i}$ are smaller than for the whole period. These results do not indicate that the underlying forces behind the comovement of the US and UK stock markets have changed markedly with the spectacular boom of the 1990's. Accordingly, as in earlier periods, the large increases in stock prices in the 1990s (leading to positive unexpected returns), was due mainly to news coming to the market that future stock market risk premia will be lower, and that this news was common to the US and UK markets. Note that in contrast to Ammer and Mei (1996), we do not interpret the high cross-country correlation of US and UK excess stock return news as indicating high financial integration of the two countries. Rather, we interpret the high correlation as an indication that risk-premia in the two countries are hit by common real shocks (c.f. the discussion in section 2.3).

On annual US and UK data (quite similar to our data) for the period 1919-1989, Beltratti and Shiller (1993) find that a simple present value model where the discount rate varies with the short-term real interest rate, can explain the comovement of US and UK stock markets. Our results do not support this finding. Within our framework, validity of Beltratti and Shiller's present value model would require the news about future excess return component to be zero, i.e. $R^{2}\left(\widetilde{e}_{e}\right)=0$, such that dividend news and real interest rate news together account for all the variability of excess return innovations. It is clear from Tables 5 and 6 that this is not the case.

As we mentioned in section 2.1, the reliability of the VAR-based variance decompositions hinges crucially on the variables in the VAR being to some extent predictable from the lagged variables in the model. Otherwise all the variability of $\tilde{e}_{t+1}^{i}$ will be attributed to the component treated as a residual. Thus, it is reassuring that when we look at Tables $2,4,5$, and 6 , a quite robust finding in all the VAR analyses is that in 
no case is the majority of the variation in $\widetilde{e}_{t+1}^{i}$ attributed to the residual news component. This makes us confident that our findings are not the result of some 'spuriously' large news component due to insufficient predictability.

Finally, it is worth noting the standard errors and $95 \%$ confidence intervals in Tables 2 to 6 . As explained in section 2.2 these are bootstrapsimulated precision measures computed by resampling the original VAR residuals. As seen, in general the $R^{2}\left(\widetilde{e}_{j}\right)$ statistics and cross-country correlation-coefficients seem to have very non-symmetric finite-sample distributions. Thus, the precision of these estimated statistics is better measured by the confidence intervals than by the standard errors.

\section{Concluding remarks}

The results in the present paper suggest that over long time-periods the international comovement of stock markets is due mainly to investors in different countries simultaneously revising their estimates of future equity risk premia. Thus, according to this explanation the stock market boom in the US and the UK in the second half of the 1990s was due to a downward revision of ex ante risk-premia in both countries, which then led to high unexpected stock returns.

Campbell and Cochrane (1999) develop a consumption-based asset pricing model with habit persistence and time-varying risk-aversion which implies that peoples risk-aversion and, hence, ex ante equity risk premia decrease during periods with higher that average economic growth (consumption growth), i.e. as in the second half of the 1990s, and increase during periods with lower that average economic growth, as in e.g. the 1970s. Thus, news that economic growth will be higher than expected makes people revise downward their required equity riskpremium. Our results are consistent with this explanation and indicate that over an 80-year period, the major shocks to economic growth have been common to the US and the UK and have induced common fluctuations in stock returns in the two countries.

\section{References}

Ammer, J., and J. Mei (1996): Measuring international economic linkages with stock market data. Journal of Finance 51, 1743-1763.

Bekaert, G., R.J. Hodrick, and D.A. Marshall (1997): On biases in tests of the expectations hypothesis of the term structure of interest rates. Journal of Financial Economics 44, 309-348.

Beltratti, A.E. and R.J. Shiller (1993): Actual and warranted relations between asset prices. Oxford Economic Papers 45, 387-402. 
Bose, A. (1988): Edgeworth correction by bootstrap in autoregressions. Annals of Statistics 16, 1709-1722.

Bulkley, G. and I. Tonks (1989): Are UK stock prices excessively volatile? Trading rules and variance bounds tests. Economic Journal 99, 1083-1098.

Campbell, J.Y. (1991): A variance decomposition for stock returns. Economic Journal 101, 157-179.

Campbell, J.Y. and J. Ammer (1993): What moves the stock and bond markets? A variance decomposition for long-term asset returns. Journal of Finance 48, 3-37.

Campbell, J.Y. and J.H. Cochrane (1999): By force of habit: A consumption based explanation of aggregate stock market bahavior. Journal of Political Economy 107, 205-251.

Campbell, J.Y. and R.J. Shiller (1988): The dividend-price ratio and expectations of future dividends and discount factors. Review of Financial Studies 1, 195-228.

Cuthbertson, K., S. Hayes, and D. Nitzsche (1997): The behaviour of UK stock prices and returns: Is the market efficient? Economic Journal 107, 986-1008.

Cuthbertson, K., S. Hayes, and D. Nitzsche (1998): Explaining movements in UK stock prices. Quarterly Review of Economics and Finance 39, 1-19.

Engsted, T. (1998): Evaluating the consumption-capital asset pricing model using Hansen-Jagannathan bounds: Evidence from the UK. International Journal of Finance and Economics 3, 291-302.

Engsted, T. and J. Lund (1997): Common stochastic trends in international stock prices and dividends: An example of testing overidentifying restrictions on multiple cointegrating vectors. Applied Financial Economics 7, 659-665.

Engsted, T. and C. Tanggaard (2001a): The Danish stock and bond markets: Comovement, return predictability and variance decomposition. Journal of Empirical Finance 8, 243-271.

Engsted, T. and C. Tanggaard (2001b): A new test for speculative bubbles based on return variance decompositions. Working paper, Aarhus School of Business.

Hall, P. (1992): The Bootstrap and Edgeworth Expansions. SpringerVerlag, New York, Inc.

Kasa, K. (1992): Common stochastic trends in international stock markets. Journal of Monetary Economics 29, 95-124.

Kilian, L. (1998): Small-sample confidence intervals for impulse response functions. Review of Economics and Statistics 80, 218-230.

Lund, J. and T. Engsted (1996): GMM and present value tests of the 
C-CAPM: Evidence from the Danish, German, Swedish, and UK stock markets. Journal of International Money and Finance 15, 497-521.

Patelis, A.D. (1997): Stock returns predictability and the role of monetary policy. Journal of Finance 52, 1951-1972.

Pope, A.L. (1990): Biases of estimators in multivariate non-gaussian autoregressions. Journal of Time Series Analysis 11, 249-258.

Shiller, R.J. (1989): Comovement in stock prices and comovement in dividends. Journal of Finance 44, 719-729.

Shiller, R.J. (2000): Irrational Exuberance. Princeton University Press.

Shiller, R.J. and A.E. Beltratti (1992): Stock prices and bond yields: Can their comovements be explained in terms of present value models? Journal of Monetary Economics 30, 25-46.

Sims, C.A. (1980): Macroeconomics and reality. Econometrica, January 1980, 1-48. 


\begin{tabular}{|c|c|c|}
\hline & $1918-1999$ & $1918-1989$ \\
\hline VAR system: & & \\
$\frac{\left\{e^{i}, r^{i}, \delta^{i}\right\}, i=u s, u k}{\mathrm{US} \text { return } R^{2}}$ & $0.231(0.000)$ & $0.340(0.000)$ \\
$\mathrm{UK}$ return $R^{2}$ & $0.250(0.000$ & $0.354(0.000)$ \\
$\left\{e^{u k}, r^{u k}, \delta^{u k}\right\} \rightarrow e^{u s}$ & 0.004 & 0.000 \\
$\left\{e^{u s}, r^{u s}, \delta^{u s}\right\} \rightarrow e^{u k}$ & 0.004 & 0.002 \\
$\mathrm{VAR}$ system: & & \\
$\left\{e^{i}, \Delta d^{i}, \delta^{i}\right\}, i=u s, u k$ & & \\
$\mathrm{US}$ return $R^{2}$ & $0.225(0.006)$ & $0.364(0.000)$ \\
$\mathrm{UK}$ return $R^{2}$ & $0.262(0.009)$ & $0.378(0.000)$ \\
$\left\{e^{u k}, r^{u k}, \delta^{u k}\right\} \rightarrow e^{u s}$ & 0.188 & 0.004 \\
$\left\{e^{u s}, r^{u s}, \delta^{u s}\right\} \rightarrow e^{u k}$ & 0.080 & 0.005 \\
\hline
\end{tabular}

Notes: The numbers in parentheses are joint significance of the explanatory variables in the excess return equations of the VAR. $\left\{e^{i}, r^{i}, \delta^{i}\right\} \rightarrow e^{j}$ denote joint significance of the $i$-country variables in the excess return regression for country $j$.

Table 1: Stock return predictability in the US and UK 


\begin{tabular}{|l|l|l|}
\hline VAR: & $\begin{array}{c}\text { United States } \\
\left.\text { Unite } r^{i}\right\}, i=u s, u k\end{array}$ & United Kingdom \\
\hline$d \rightarrow r \rightarrow e:$ & & \\
$R^{2}\left(\widetilde{e}_{d}\right)$ & $\mathbf{0 . 1 3 4}(0.239)[0.000,0.717]$ & $\mathbf{0 . 0 1 6}(0.102)[0.000,0.180]$ \\
$R^{2}\left(\widetilde{e}_{r}\right)$ & $\mathbf{0 . 4 7 8}(0.173)[0.345,0.955]$ & $\mathbf{0 . 2 1 1}(0.122)[0.047,0.768]$ \\
$R^{2}\left(\widetilde{e}_{e}\right)$ & $\mathbf{0 . 3 8 8}(0.236)[0.018,0.738]$ & $\mathbf{0 . 7 7 3}(0.146)[0.305,0.968]$ \\
$r \rightarrow d \rightarrow e:$ & & \\
$R^{2}\left(\widetilde{e}_{d}\right)$ & $\mathbf{0 . 1 3 1}(0.183)[0.000,0.626]$ & $\mathbf{0 . 0 0 5}(0.083)[0.000,0.052]$ \\
$R^{2}\left(\widetilde{e}_{r}\right)$ & $\mathbf{0 . 4 8 1}(0.179)[0.323,0.861]$ & $\mathbf{0 . 2 2 2}(0.131)[0.042,0.757]$ \\
$R^{2}\left(\widetilde{e}_{e}\right)$ & $\mathbf{0 . 3 8 8}(0.236)[0.018,0.738]$ & $\mathbf{0 . 7 7 3}(0.146)[0.305,0.968]$ \\
$d \rightarrow e \rightarrow r:$ & & \\
$R^{2}\left(\widetilde{e}_{d}\right)$ & $\mathbf{0 . 1 3 4}(0.239)[0.000,0.717]$ & $\mathbf{0 . 0 1 6}(0.102)[0.000,0.180]$ \\
$R^{2}\left(\widetilde{e}_{r}\right)$ & $\mathbf{0 . 1 2 8}(0.072)[0.040,0.303]$ & $\mathbf{0 . 1 7 6}(0.074)[0.085,0.575]$ \\
$R^{2}\left(\widetilde{e}_{e}\right)$ & $\mathbf{0 . 7 3 9}(0.240)[0.226,0.948]$ & $\mathbf{0 . 8 0 8}(0.122)[0.477,0.938]$ \\
$r \rightarrow e \rightarrow d:$ & & \\
$R^{2}\left(\widetilde{e}_{d}\right)$ & $\mathbf{0 . 3 7 7}(0.136)[0.174,0.719]$ & $\mathbf{0 . 3 4 9}(0.128)[0.177,0.764]$ \\
$R^{2}\left(\widetilde{e}_{r}\right)$ & $\mathbf{0 . 4 8 1}(0.179)[0.323,0.861]$ & $\mathbf{0 . 2 2 2}(0.131)[0.042,0.757]$ \\
$R^{2}\left(\widetilde{e}_{e}\right)$ & $\mathbf{0 . 1 4 2}(0.193)[0.000,0.300]$ & $\mathbf{0 . 4 2 9}(0.166)[0.030,0.647]$ \\
$e \rightarrow d \rightarrow r:$ & & \\
$R^{2}\left(\widetilde{e}_{d}\right)$ & $\mathbf{0 . 2 5 8}(0.139)[0.053,0.550]$ & $\mathbf{0 . 1 9 0}(0.116)[0.033,0.499]$ \\
$R^{2}\left(\widetilde{e}_{r}\right)$ & $\mathbf{0 . 1 2 8}(0.072)[0.040,0.303]$ & $\mathbf{0 . 1 7 6}(0.074)[0.085,0.575]$ \\
$R^{2}\left(\widetilde{e}_{e}\right)$ & $\mathbf{0 . 6 1 4}(0.140)[0.360,0.832]$ & $\mathbf{0 . 6 3 4}(0.134)[0.241,0.825]$ \\
$e \rightarrow r \rightarrow d:$ & & \\
$R^{2}\left(\widetilde{e}_{d}\right)$ & $\mathbf{0 . 3 7 7}(0.136)[0.174,0.719]$ & $\mathbf{0 . 3 4 9}(0.128)[0.177,0.764]$ \\
$R^{2}\left(\widetilde{e}_{r}\right)$ & $\mathbf{0 . 0 0 8}(0.069)[0.000,0.093]$ & $\mathbf{0 . 0 1 7}(0.047)[0.000,0.180]$ \\
$R^{2}\left(\widetilde{e}_{e}\right)$ & $\mathbf{0 . 6 1 4}(0.140)[0.360,0.832]$ & $\mathbf{0 . 6 3 4}(0.134)[0.241,0.825]$ \\
\hline
\end{tabular}

Notes: The numbers in bold are point estimates based on the bias-adjusted VAR parameter estimates. The numbers in parentheses and brackets are bootstrap standard errors and $95 \%$ confidence intervals, respectively, based on 100.000 bootstrap simulations.

Table 2: Variance decomposition for excess stock returns, 1918-1999. 


\begin{tabular}{|c|c|c|}
\hline & $1918-1999$ & $1918-1989$ \\
\hline VAR: $\left\{e^{i}, r^{i}, \delta^{i}\right\}$ & & \\
$i=u s, u k$ & & \\
$\operatorname{Corr}\left(\widetilde{e}_{d}^{u s}, \widetilde{e}_{d}^{u k}\right)$ & $\mathbf{0 . 6 3 5}(0.225)[0.051,0.906]$ & $\mathbf{0 . 7 6 0}(0.193)[0.216,0.943]$ \\
$\operatorname{Corr}\left(\widetilde{e}_{r}^{u s}, \widetilde{e}_{r}^{u k}\right)$ & $\mathbf{0 . 9 4 3}(0.092)[0.744,0.973]$ & $\mathbf{0 . 9 5 8}(0.055)[0.814,0.978]$ \\
$\operatorname{Corr}\left(\widetilde{e}_{e}^{u s}, \widetilde{e}_{e}^{u k}\right)$ & $\mathbf{0 . 8 9 2}(0.158)[0.383,0.936]$ & $\mathbf{0 . 6 1 6}(0.206)[0.080,0.872]$ \\
& & \\
\hline VAR: $\left\{e^{i}, \Delta d^{i}, \delta^{i}\right\}$ & & \\
$i=u s, u k$ & & \\
$\operatorname{Corr}\left(\widetilde{e}_{d}^{u s}, \widetilde{e}_{d}^{u k}\right)$ & $\mathbf{0 . 8 2 3}(0.182)[0.248,0.935]$ & $\mathbf{0 . 6 3 3}(0.248)[0.011,0.942]$ \\
$\operatorname{Corr}\left(\widetilde{e}_{r}^{u s}, \widetilde{e}_{r}^{u k}\right)$ & $\mathbf{0 . 8 8 0}(0.110)[0.551,0.956]$ & $\mathbf{0 . 9 5 0}(0.076)[0.728,0.975]$ \\
$\operatorname{Corr}\left(\widetilde{e}_{e}^{u s}, \widetilde{e}_{e}^{u k}\right)$ & $\mathbf{0 . 8 5 5}(0.143)[0.408,0.929]$ & $\mathbf{0 . 5 8 6}(0.237)[-0.026,0.877]$ \\
\hline
\end{tabular}

Notes: The numbers in bold are correlation coefficients based on the biasadjusted VAR parameter estimates. The numbers in parentheses and brackets are bootstrap standard errors and 95\% confidence intervals, respectively, based on 100.000 bootstrap simulations.

Table 3: Cross-country correlations of news components 


\begin{tabular}{|c|c|c|}
\hline$\overline{\mathrm{VA}}$ & $\begin{array}{c}\left\{e^{i}, \Delta d^{i}, \delta^{i}\right\}, i=u s, u k \\
\text { United States }\end{array}$ & $\begin{array}{l}\text { 1918-1999 } \\
\text { United Kingdom }\end{array}$ \\
\hline \multicolumn{3}{|l|}{$d \rightarrow r \rightarrow \epsilon$} \\
\hline$R^{2}\left(\widetilde{e}_{d}\right)$ & $\mathbf{0 . 0 2 2}(0.150)[0.000,0.264]$ & $\mathbf{0 . 0 5 1}(0.095)[0.000,0.365]$ \\
\hline$R^{2}\left(\widetilde{e}_{r}\right)$ & $\mathbf{0 . 0 2 8}(0.128)[0.000,0.294]$ & $\mathbf{0 . 0 9 3}(0.095)[0.004,0.516]$ \\
\hline$R^{2}\left(\widetilde{e}_{e}\right)$ & $\mathbf{0 . 9 5 0}(0.190)[0.801,1.000]$ & $\mathbf{0 . 8 5 6}(0.125)[0.514,0.992]$ \\
\hline \multicolumn{3}{|l|}{$r \rightarrow d \rightarrow e:$} \\
\hline$R^{2}\left(\widetilde{e}_{d}\right)$ & $\mathbf{0 . 0 1 4}(0.160)[0.000,0.179]$ & $\mathbf{0 . 0 7 8}(0.092)[0.002,0.480]$ \\
\hline$R^{2}\left(\widetilde{e}_{r}\right)$ & $\mathbf{0 . 0 3 6}(0.114)[0.000,0.312]$ & $\mathbf{0 . 0 6 6}(0.097)[0.001,0.421]$ \\
\hline$R^{2}\left(\widetilde{e}_{e}\right)$ & $\mathbf{0 . 9 5 0}(0.190)[0.801,1.000]$ & $\mathbf{0 . 8 5 6}(0.125)[0.514,0.992]$ \\
\hline \multicolumn{3}{|l|}{$d \rightarrow e \rightarrow r:$} \\
\hline$R^{2}\left(\widetilde{e}_{d}\right)$ & $\mathbf{0 . 0 2 2}(0.150)[0.000$, & $\mathbf{0 . 0 5 1}(0.095)[0.000$ \\
\hline$R^{2}\left(\widetilde{e}_{r}\right)$ & $\mathbf{0 . 2 1 6}(0.108)[0.086,0.550]$ & $\mathbf{0 . 1 2 7}(0.058)[0.058,0.388]$ \\
\hline$R^{2}\left(\widetilde{e}_{e}\right)$ & $\mathbf{0 . 7 6 2}(0.177)[0.442,0.932]$ & $\mathbf{0 . 8 2 2}(0.107)[0.505,0.940]$ \\
\hline \multicolumn{3}{|l|}{$r \rightarrow e \rightarrow d:$} \\
\hline$R^{2}\left(\widetilde{e}_{d}\right)$ & $\mathbf{0 . 3 4 1}(0.119)[0.169,0.690]$ & $\mathbf{0 . 3 3 1}(0.126)[0.161,0.733]$ \\
\hline$R^{2}\left(\widetilde{e}_{r}\right)$ & $\mathbf{0 . 0 3 6}(0.114)[0.000,0.312]$ & $\mathbf{0 . 0 6 6}(0.097)[0.001,0.421]$ \\
\hline$R^{2}\left(\widetilde{e}_{e}\right)$ & $\mathbf{0 . 6 2 4}(0.155)[0.289,0.858]$ & $\mathbf{0 . 6 0 3}(0.148)[0.216,0.825]$ \\
\hline \multicolumn{3}{|l|}{$e \rightarrow d \rightarrow r:$} \\
\hline$R^{2}\left(\widetilde{e}_{d}\right)$ & $\mathbf{0 . 2 0 7}(0.127)[0.021,0.509]$ & $\mathbf{0 . 2 0 4}(0.118)[0.045,0.539]$ \\
\hline$R^{2}\left(\widetilde{e}_{r}\right)$ & $\mathbf{0 . 2 1 6}(0.108)[0.086,0.550]$ & $\mathbf{0 . 1 2 7}(0.058)[0.058,0.388]$ \\
\hline$R^{2}\left(\widetilde{e}_{e}\right)$ & $\mathbf{0 . 5 7 7}(0.142)[0.261,0.805]$ & $\mathbf{0 . 6 6 9}(0.133)[0.303,0.857]$ \\
\hline \multicolumn{3}{|l|}{$e \rightarrow r \rightarrow d:$} \\
\hline$R^{2}\left(\widetilde{e}_{d}\right)$ & $\mathbf{0 . 3 4 1}(0.119)[0.169,0.690]$ & $\mathbf{0 . 3 3 1}(0.126)[0.161,0.733]$ \\
\hline$R^{2}\left(\widetilde{e}_{r}\right)$ & $\mathbf{0 . 0 8 2}(0.107)[0.000,0.330]$ & $\mathbf{0 . 0 0 0}(0.038)[0.000,0.001]$ \\
\hline$R^{2}\left(\widetilde{e}_{e}\right)$ & $\mathbf{0 . 5 7 7}(0.142)[0.261,0.805]$ & $\mathbf{0 . 6 6 9}(0.133)[0.303,0.857]$ \\
\hline
\end{tabular}

Notes: The numbers in bold are point estimates based on the bias-adjusted VAR parameter estimates. The numbers in parentheses and brackets are bootstrap standard errors and $95 \%$ confidence intervals, respectively, based on 100.000 bootstrap simulations.

Table 4: Variance decomposition for excess stock returns, 1918-1999. 


\begin{tabular}{|c|c|c|}
\hline$\overline{\text { VAR }}$ & $\begin{array}{c}\left\{e^{i}, r^{i}, \delta^{i}\right\}, i=u s, u k \\
\text { United States }\end{array}$ & $\begin{array}{l}\text { 1918-1989 } \\
\text { United Kingdom }\end{array}$ \\
\hline \multicolumn{3}{|l|}{$d \rightarrow r \rightarrow$} \\
\hline$R^{2}\left(\widetilde{e}_{d}\right)$ & $\mathbf{0 . 2 8 4}(0.222)[0.007,0.862]$ & $\mathbf{0 . 1 7 2}(0.161)[0.003,0.655]$ \\
\hline$R^{2}\left(\widetilde{e}_{r}\right)$ & $\mathbf{0 . 0 8 0}(0.118)[0.001,0.588]$ & $\mathbf{0 . 0 1 4}(0.118)[0.000,0.157]$ \\
\hline$R^{2}\left(\widetilde{e}_{e}\right)$ & $\mathbf{0 . 6 3 6}(0.226)[0.121,0.968]$ & $\mathbf{0 . 8 1 4}(0.193)[0.395,0.997]$ \\
\hline \multicolumn{3}{|l|}{$r \rightarrow d \rightarrow e:$} \\
\hline$R^{2}\left(\widetilde{e}_{d}\right)$ & $\mathbf{0 . 0 8 7}(0.182)[0.000,0.530]$ & $\mathbf{0 . 0 9 6}(0.168)[0.000,0.519]$ \\
\hline$R^{2}\left(\widetilde{e}_{r}\right)$ & $\mathbf{0 . 2 7 8}(0.157)[0.051,0.800]$ & $\mathbf{0 . 0 9 0}(0.106)[0.002,0.495]$ \\
\hline$R^{2}\left(\widetilde{e}_{e}\right)$ & $\mathbf{0 . 6 3 6}(0.226)[0.121,0.968]$ & $\mathbf{0 . 8 1 4}(0.193)[0.395,0.997]$ \\
\hline \multicolumn{3}{|l|}{$d \rightarrow e \rightarrow r:$} \\
\hline$R^{2}\left(\widetilde{e}_{d}\right)$ & $\mathbf{0 . 2 8 4}(0.222)[0.007$ & $\mathbf{0 . 1 7 2}(0.161)[0.00$ \\
\hline$R^{2}\left(\widetilde{e}_{r}\right)$ & $\mathbf{0 . 2 7 4}(0.122)[0.109$, & $\mathbf{0 . 1 9 7}(0.094)[0.083,0.560]$ \\
\hline$R^{2}\left(\widetilde{e}_{e}\right)$ & $\mathbf{0 . 4 4 2}(0.221)[0.010,0.794]$ & $\mathbf{0 . 6 3 1}(0.182)[0.145,0.876]$ \\
\hline \multicolumn{3}{|l|}{$r \rightarrow e \rightarrow d:$} \\
\hline$R^{2}\left(\widetilde{e}_{d}\right)$ & $\mathbf{0 . 5 3 1}(0.168)[0.259,0.915]$ & $\mathbf{0 . 3 0 5}(0.144)[0.122,0.748]$ \\
\hline$R^{2}\left(\widetilde{e}_{r}\right)$ & $\mathbf{0 . 2 7 8}(0.157)[0.051,0.800]$ & $\mathbf{0 . 0 9 0}(0.106)[0.002,0.495]$ \\
\hline$R^{2}\left(\widetilde{e}_{e}\right)$ & $\mathbf{0 . 1 9 2}(0.184)[0.000,0.506]$ & $\mathbf{0 . 6 0 5}(0.171)[0.165,0.848]$ \\
\hline \multicolumn{3}{|l|}{$e \rightarrow d \rightarrow r:$} \\
\hline$R^{2}\left(\widetilde{e}_{d}\right)$ & $\mathbf{0 . 2 5 8}(0.181)[0.009,0.640]$ & $\mathbf{0 . 1 1 4}(0.137)[0.001,0.454]$ \\
\hline$R^{2}\left(\widetilde{e}_{r}\right)$ & $\mathbf{0 . 2 7 4}(0.122)[0.109,0.624]$ & $\mathbf{0 . 1 9 7}(0.094)[0.083,0.560]$ \\
\hline$R^{2}\left(\widetilde{e}_{e}\right)$ & $\mathbf{0 . 4 6 8}(0.174)[0.126,0.765]$ & $\mathbf{0 . 6 8 8}(0.162)[0.277,0.891]$ \\
\hline \multicolumn{3}{|l|}{$e \rightarrow r \rightarrow d:$} \\
\hline$R^{2}\left(\widetilde{e}_{d}\right)$ & $\mathbf{0 . 5 3 1}(0.168)[0.259$, & $\mathbf{0 . 3 0 5}(0.144)[0.122,0.748]$ \\
\hline$R^{2}\left(\widetilde{e}_{r}\right)$ & $\mathbf{0 . 0 0 2}(0.078)[0.000,0.015]$ & $\mathbf{0 . 0 0 7}(0.066)[0.000,0.086]$ \\
\hline$R^{2}\left(\widetilde{e}_{e}\right)$ & $\mathbf{0 . 4 6 8}(0.174)[0.126,0.765]$ & $\mathbf{0 . 6 8 8}(0.162)[0.277,0.891]$ \\
\hline
\end{tabular}

Notes: The numbers in bold are point estimates based on the bias-adjusted VAR parameter estimates. The numbers in parentheses and brackets are bootstrap standard errors and $95 \%$ confidence intervals, respectively, based on 100.000 bootstrap simulations.

Table 5: Variance decomposition for excess stock returns, 1918-1989. 


\begin{tabular}{|c|c|c|}
\hline$\overline{\mathrm{VA}}$ & $\begin{array}{c}\left\{e^{i}, \Delta d^{i}, \delta^{i}\right\}, i=u s, u k \\
\text { United States }\end{array}$ & $\begin{array}{l}\text { 1918-1989 } \\
\text { United Kingdom }\end{array}$ \\
\hline \multicolumn{3}{|l|}{$d \rightarrow r \rightarrow \epsilon$} \\
\hline$R^{2}\left(\widetilde{e}_{d}\right)$ & $\mathbf{0 . 0 5 1}(0.173)[0.000,0.456]$ & $\mathbf{0 . 0 8 7}(0.137)[0.000,0.522]$ \\
\hline$R^{2}\left(\widetilde{e}_{r}\right)$ & $\mathbf{0 . 0 6 1}(0.119)[0.000,0.496]$ & $\mathbf{0 . 0 0 0}(0.107)[0.000,0.001]$ \\
\hline$R^{2}\left(\widetilde{e}_{e}\right)$ & $\mathbf{0 . 8 8 7}(0.200)[0.538,0.999]$ & $\mathbf{0 . 9 1 2}(0.169)[0.655,1.000]$ \\
\hline \multicolumn{3}{|l|}{$r \rightarrow d \rightarrow e:$} \\
\hline$R^{2}\left(\widetilde{e}_{d}\right)$ & $\mathbf{0 . 0 2 5}(0.177)[0.000,0.252]$ & $\mathbf{0 . 0 2 7}(0.139)[0.000,0.245]$ \\
\hline$R^{2}\left(\widetilde{e}_{r}\right)$ & $\mathbf{0 . 0 8 8}(0.106)[0.002,0.526]$ & $\mathbf{0 . 0 6 1}(0.100)[0.000,0.407]$ \\
\hline$R^{2}\left(\widetilde{e}_{e}\right)$ & $\mathbf{0 . 8 8 7}(0.200)[0.538,0.999]$ & $\mathbf{0 . 9 1 2}(0.169)[0.655,1.000]$ \\
\hline \multicolumn{3}{|l|}{$d \rightarrow e \rightarrow r:$} \\
\hline$R^{2}\left(\widetilde{e}_{d}\right)$ & $\mathbf{0 . 0 5 1}(0.173)[0.000$, & $\mathbf{0 . 0 8 7}(0.137)[0.000,0.522]$ \\
\hline$R^{2}\left(\widetilde{e}_{r}\right)$ & $\mathbf{0 . 4 1 1}(0.166)[0.178$ & $\mathbf{0 . 1 7 0}(0.078)[0.079,0.567]$ \\
\hline$R^{2}\left(\widetilde{e}_{e}\right)$ & $\mathbf{0 . 5 3 7}(0.210)[0.099,0.860]$ & $\mathbf{0 . 7 4 3}(0.158)[0.269,0.922]$ \\
\hline \multicolumn{3}{|l|}{$r \rightarrow e \rightarrow d:$} \\
\hline$R^{2}\left(\widetilde{e}_{d}\right)$ & $\mathbf{0 . 5 5 0}(0.174)[0.270,0.947]$ & $\mathbf{0 . 3 1 8}(0.139)[0.141,0.788]$ \\
\hline$R^{2}\left(\widetilde{e}_{r}\right)$ & $\mathbf{0 . 0 8 8}(0.106)[0.002,0.526]$ & $\mathbf{0 . 0 6 1}(0.100)[0.000,0.407]$ \\
\hline$R^{2}\left(\widetilde{e}_{e}\right)$ & $\mathbf{0 . 3 6 2}(0.184)[0.011,0.685]$ & $\mathbf{0 . 6 2 1}(0.163)[0.193,0.850]$ \\
\hline \multicolumn{3}{|l|}{$e \rightarrow d \rightarrow r:$} \\
\hline$R^{2}\left(\widetilde{e}_{d}\right)$ & $\mathbf{0 . 1 8 2}(0.180)[0.000$ & $\mathbf{0 . 1 8 8}(0.162)[0.007,0.574]$ \\
\hline$R^{2}\left(\widetilde{e}_{r}\right)$ & $\mathbf{0 . 4 1 1}(0.166)[0.178,0.882]$ & $\mathbf{0 . 1 7 0}(0.078)[0.079,0.567]$ \\
\hline$R^{2}\left(\widetilde{e}_{e}\right)$ & $0.407(0.175)[0.075,0.735]$ & $\mathbf{0 . 6 4 3}(0.174)[0.189,0.877]$ \\
\hline \multicolumn{3}{|l|}{$e \rightarrow r \rightarrow d:$} \\
\hline$R^{2}\left(\widetilde{e}_{d}\right)$ & $\mathbf{0 . 5 5 0}(0.174)[0.270$ & $\mathbf{0 . 3 1 8}(0.139)[0.1$ \\
\hline$R^{2}\left(\widetilde{e}_{r}\right)$ & $\mathbf{0 . 0 4 3}(0.114)[0.000,0.312]$ & $\mathbf{0 . 0 3 9}(0.103)[0.000,0.339]$ \\
\hline$R^{2}\left(\widetilde{e}_{e}\right)$ & $\mathbf{0 . 4 0 7}(0.175)[0.075,0.735]$ & $\mathbf{0 . 6 4 3}(0.174)[0.189,0.877]$ \\
\hline
\end{tabular}

Notes: The numbers in bold are point estimates based on the bias-adjusted VAR parameter estimates. The numbers in parentheses and brackets are bootstrap standard errors and $95 \%$ confidence intervals, respectively, based on 100.000 bootstrap simulations.

Table 6: Variance decomposition for excess stock returns, 1918-1989. 


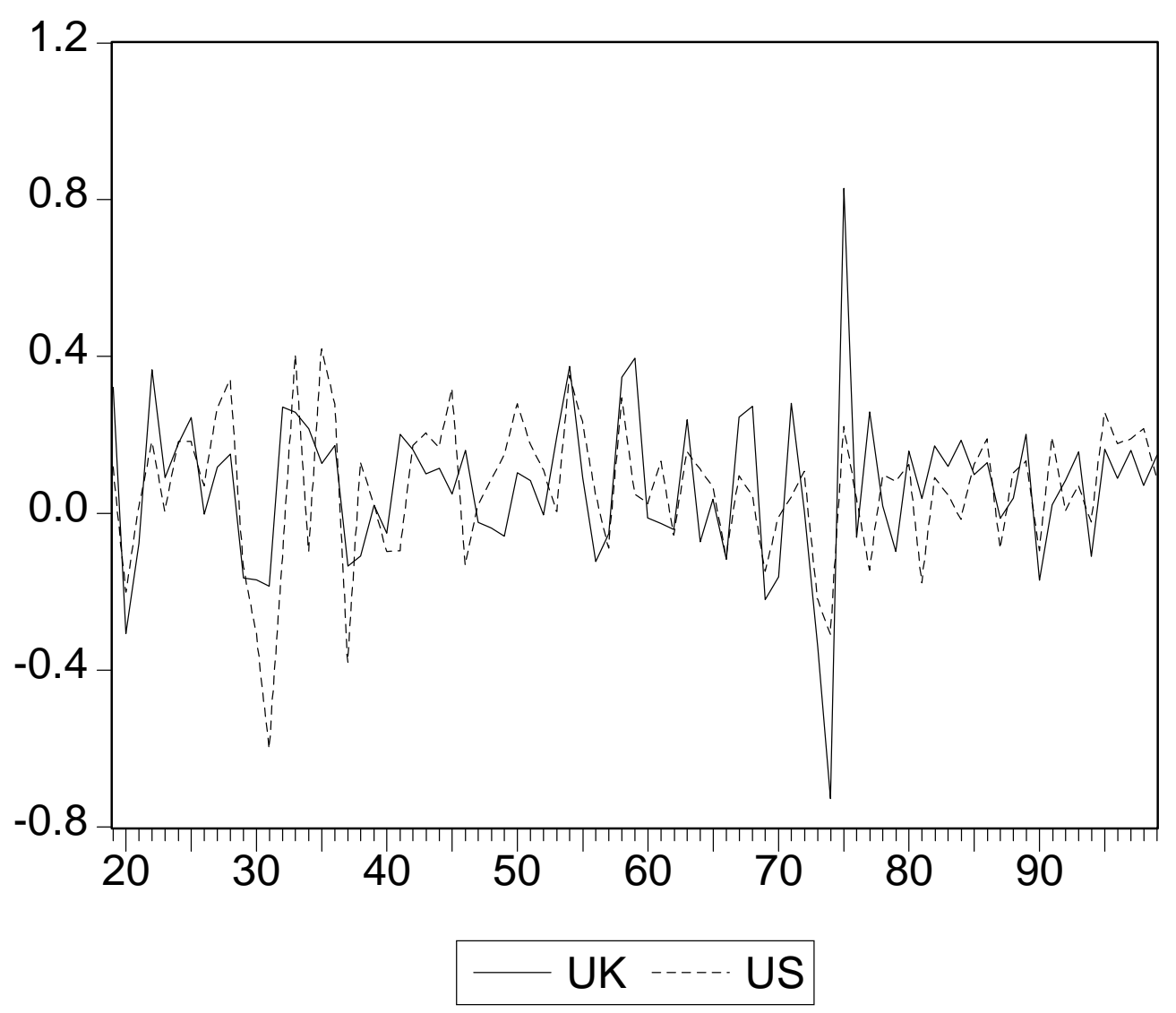

Figure 1: US and UK log excess stock returns, 1919-1999 